\title{
IMPACTS OF TRANSVERSE EARTHQUAKES ON SEISMIC RESPONSE OF BRIDGES WITH ROCKING FOUNDATIONS AND VARIOUS SHEAR KEYS
}

\author{
OMAR EL-HAWAT ${ }^{1 *}$, BEHZAD FATAHI $^{1 \dagger} \&$ AMIR A. MOSAVI ${ }^{2}$ \\ ${ }^{1}$ School of Civil \& Environmental Engineering, University of Technology Sydney (UTS), Australia \\ ${ }^{2}$ ARUP, USA
}

\begin{abstract}
Rocking foundations are proven to be an effective base isolation technique that improves the seismic performance of bridges and minimises the damage at the piers during large earthquakes. However, due to the foundations ability to uplift, the subsequent reduction of the pier's stiffness leads to larger column drifts and deck displacements. This not only attracts larger stresses to the transverse direction of the deck, but also at the abutment which, if not carefully considered, can lead to severe damages. Therefore, this study will investigate the seismic response of bridges with rocking pile foundations subjected to transverse earthquake excitations and compare it to the response of conventional fixed base bridges. Two separate shear key performance levels are investigated for each bridge: (1) non-linear shear keys that break off; and (2) shear keys that remain rigid. 3D numerical models of the bridges are developed using finite element software with consideration of soil-structure interaction. Moreover, non-linear time history analyses are performed on the bridges using four ground-motion records, where their dynamic response are then compared. Results show that the conventional bridges collapsed due to the development of plastic hinging at the piers. However, the bridges with the rocking pile foundations experienced significant deck displacements which caused flexural plastic hinging of the deck and the subsequent collapse of the bridge. Moreover, when the shear keys failed, the deck experienced large displacements at the abutment which caused the bearing to rupture and displace permanently with the risk of unseating and span failure. Bridges with this foundation system will require additional design provisions to prevent such failures from occurring.

Keywords: rocking foundations, soil-structure interaction, shear key, base isolation, time history analysis.
\end{abstract}

\section{INTRODUCTION}

Conventional bridges with fixed base foundations are designed to withstand seismic loading through the development of plastic hinges at their piers. However, the inelastic damage caused by the formation of these hinges often necessitate lengthy repairs, traffic disturbances and in severe cases, demolition of the entire bridge [1].

Rocking isolation can be utilized in the design of bridges as an effective base isolation mechanism to improve the structures seismic performance [2], [3]. This not only reduces the seismic demand on the structure, but also significantly reduces the damage caused by inelastic behaviour at the piers. Two common methods for implementing rocking isolation in bridge design are: rocking shallow foundations and rocking pile foundations. Rocking shallow foundations have been studied in various numerical, analytical and experimental studies [4], [5]. It was found that the use of rocking shallow foundations can significantly reduce the seismic demand as well as inelastic damage caused to the bridge, whereas otherwise would cause structural collapse. However, excessive foundation settlement and residual soil rotation were experienced as a result of footing uplift. If not accounted for in the

*ORCID: http://orcid.org/0000-0003-0186-0769

${ }^{\dagger}$ ORCID: http://orcid.org/0000-0002-7920-6946 
design of the bridge, this could lead to other damages within the structure [4]. On the contrary, the rocking pile foundation implements piles as part of the rocking foundation system to significantly reduce the inelastic behaviour of the soil. Yet, the absence of energy dissipation that would otherwise arise from the formation of plastic hinging at the piers and plastic deformation of the soil, causes the bridge to experience larger deck displacements and column drifts [2]. This cannot only attract larger forces to the deck but also at the abutment, and if not carefully considered, can lead to significant damage to the superstructure.

The lateral stiffness of the pier and footing can significantly affect the seismic response of the bridge, particularly the response of the deck. When the rocking foundation is utilised in the design of the bridge, the lateral stiffness of the pier and foundation is purely dependant on its self-centring capacity rather than its bending stiffness [6]. Due to the significant decrease in the lateral stiffness of the pier and foundation due to uplift, the bridge behaves more like a long span bridge, spanning from both abutments. As observed from previous earthquakes such as in the 1999 Chi-Chi Taiwan earthquake [7], some damages that were experienced with long span bridges were critical for the transverse direction. Some of these damages included deck flexural hinging, as well as local failure of the bridge deck flanges and webs [7]. Such damage is not only very expensive to repair but can also lead to span failure and possible collapse of the entire bridge deck. Therefore, it is of importance to investigate the transverse response of bridges with rocking foundation for their reduced lateral stiffness to the deck.

The connection between the bridge deck and the abutment plays a crucial role for the transverse response of the bridge under large earthquake shaking. Shear keys are used in abutments to provide transverse restraint for the deck against seismic loading [8]. Generally, the shear keys are designed to be sacrificial to limit the forces transferred to the abutments and piles; and prevent damage from occurring as they are expensive and difficult to repair. According to the Caltrans seismic design code [9], the strength of shear keys must not exceed either $75 \%$ of the total shear capacity of the piles and $30 \%$ of the total vertical dead load reaction at the abutments [10]. The strength limit of the shear keys is completely independent of the transverse load generated by the deck and can either break off or remain rigid in the event of a maximum considered earthquake (MCE). Despite designing the shear keys to protect the abutment, if too weak, they will fracture and could lead to transverse unseating of the bridge deck as well as bearing rupture [11]. Conversely, if the shear keys are too rigid, this can encourage flexural hinging of the deck and possible collapse of the bridge as mentioned earlier [7]. Limited research is conducted on the transverse seismic response of bridges with rocking foundations or the effect of shear keys on the seismic performance of the deck. Therefore, it is of importance to investigate the effect of transverse earthquake excitations on the seismic response of bridges with rocking foundations and various shear keys.

\section{BRIDGE DESCRIPTION}

The bridges adopted in this study represent a typical highway bridge located in a high seismic region of Europe. A total of four bridges are investigated in this paper. Two bridges adopt a rocking pile (RP) foundation designed to uplift and rock about the piles, and two bridges adopt a fixed base (FB) foundation designed to develop plastic hinging at the pier base. The two bridges for each foundation systems will have two different shear key performance levels: (1) non-linear shear keys that break off and cease to provide transverse restraint, hereby referred to as sacrificial shear keys; and (2) shear keys that do not break off and continue to provide transverse restraint throughout earthquake shaking, hereby referred to as 


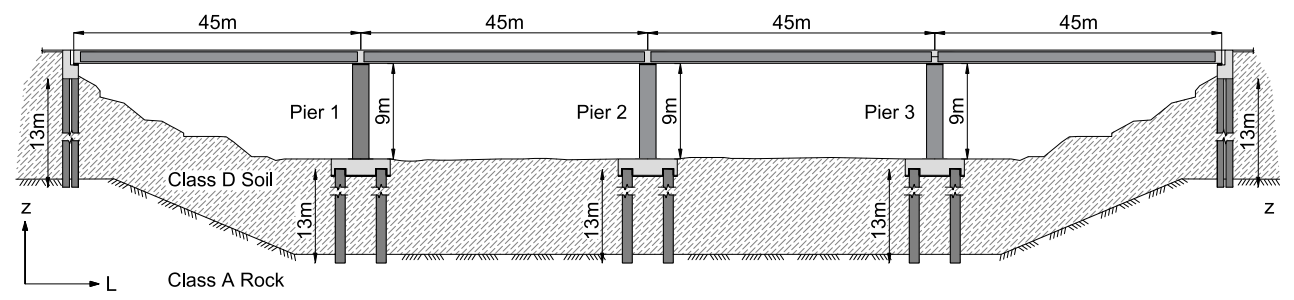

Figure 1: Longitudinal section of the bridge adopted in this study.

rigid shear keys. The bridges are designed to comply with Eurocode- 8 and created with geometries similar to existing bridges within the same seismic region. Fig. 1 presents the bridge configuration and geometries adopted for all the bridges.

The concrete bridge is symmetrical with four equal length spans of $45 \mathrm{~m}$ and a total length of $180 \mathrm{~m}$. The concrete deck comprises a continuous box girder with a total width of $14 \mathrm{~m}$ and a depth of $1.85 \mathrm{~m}$. The box girder deck has two external and two internal girders. All slabs and girders have a thickness of $0.27 \mathrm{~m}$ and longitudinal reinforcement of $2 \%$. The bridge is supported by three intermediate piers with an equal height of $9 \mathrm{~m}$. The concrete piers comprise a hollow rectangular section of $2.4 \mathrm{~m} \times 4.4 \mathrm{~m}$ with wall thicknesses of $0.50 \mathrm{~m}$ and longitudinal reinforcement of $2 \%$. All the concrete used in the bridge has a compressive strength of $50 \mathrm{MPa}$ and a unit weight of $25 \mathrm{kN} / \mathrm{m}^{3}$. Furthermore, the reinforcing steel has a yield strength of $480 \mathrm{MPa}$ and a unit weight of $77 \mathrm{kN} / \mathrm{m}^{3}$.

The bridge piers are supported by pile cap foundations connected to four piles. The pile cap has square dimensions of $7.2 \mathrm{~m} \times 7.2 \mathrm{~m}$ and thickness of $1.9 \mathrm{~m}$. The piles are $1.2 \mathrm{~m}$ in diameter with longitudinal reinforcing of $1.5 \%$. For the FB bridge, the piles are fixed to the pile cap whereas in the RP bridge the piles are unconnected to allow pile-cap uplift. Additionally, the piles protrude $0.4 \mathrm{~m}$ into the pile cap for the RP bridge for the adequate transfer of forces throughout the earthquake shaking.

The bridge deck is supported by four elastomeric bearings at the abutments. The bearings have square dimensions of $0.65 \mathrm{~m} \times 0.65 \mathrm{~m}$ and an overall height of $0.2 \mathrm{~m}$. The piles at the abutment are $0.8 \mathrm{~m}$ in diameter and have longitudinal reinforcing of $1.5 \%$. All piles are founded in soft clay with properties classifying it into Class D soil, and end bearing with $1 \mathrm{~m}$ socket into class A rock as defined in Eurocode-8 [12].

\section{NUMERICAL MODEL}

Three dimensional models of the bridges were developed using the finite element software SAP2000 V20.1 as displayed in Fig. 2. The bridge deck is modelled using multiple frame elements with lumped masses [13]. The frame elements are characterised to capture axial, bending, shear, and torsional actions in every direction. As presented in Figs 2 and 3(a), a flexural plastic hinge is assigned to the midspan of the deck (Fibre M2-M3), and at the base of the piers (Fibre P-M2-M3) to capture possible inelastic behaviour that may occur during the seismic loading. All assigned flexural hinges adopt a Takeda type hysteresis for the concrete, and a kinematic hardening type hysteresis for the reinforcing steel. The piers are modelled using frame elements and connected to the underside of deck using hinge type connections to allow rotation while resisting lateral displacements. Furthermore, Eurocode8 [12] requires that the bending stiffness of the piers are reduced by $35 \%$ to account for flexural cracking in the tensile regions of the concrete during the earthquake loading [13]. 


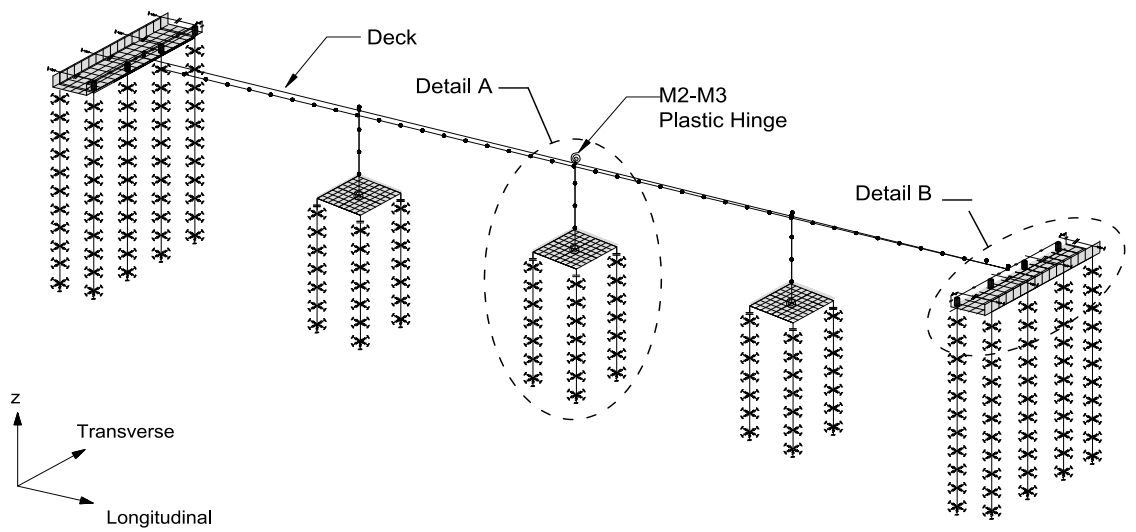

Figure 2: Schematic diagram of the numerical model of the bridges.
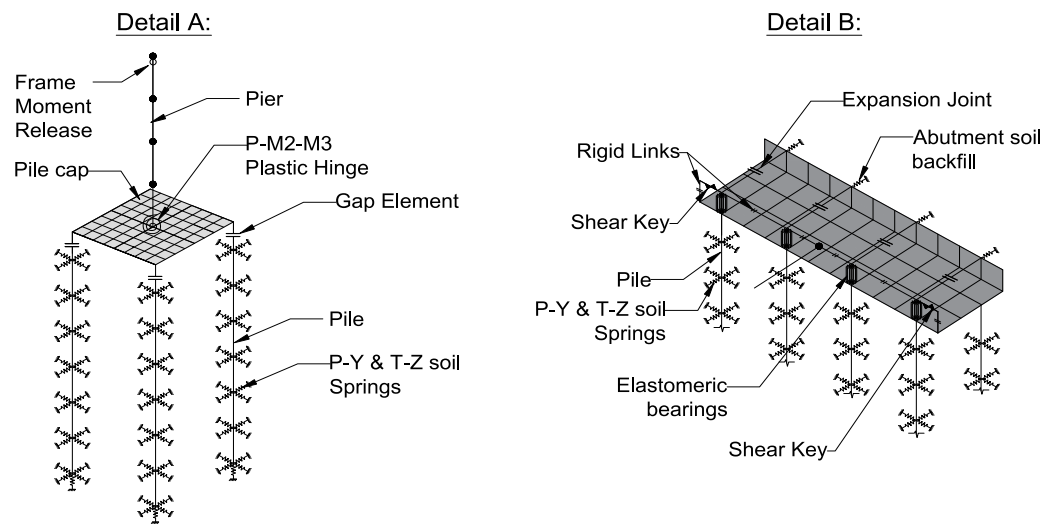

Figure 3: (a) Numerical model of the pier and rocking pile foundation system; (b) Numerical model of the abutment.

The abutments are modelled as shell elements while the piles are modelled as frame elements as displayed in Fig. 3(b). Multi-linear plastic springs are used behind the abutment backwall to model the passive capacity of the soil in accordance with Caltrans [9]. The springs are spaced at $2 \mathrm{~m}$ intervals with a compressive stiffness of $28.7 \mathrm{kPa} / \mathrm{mm} / \mathrm{m}$ with an upper bound limit of $6.2 \mathrm{kN}$. These springs are only activated once the expansion joint is closed and the deck makes contact with the abutment. The expansion joint is modelled using a gap element with an opening of $0.3 \mathrm{~m}$ and compressive stiffness equal to the stiffness of the deck [14]. Furthermore, the elastomeric bearings are modelled with multi-linear plastic springs with horizontal stiffness given by eqn (1) [2]:

$$
k_{h}=\frac{G_{r} A}{t_{r}},
$$

where $G_{r}$ is the shear modulus of the rubber taken to be $0.9 \mathrm{MPa}, A$ is the plan area of the bearing and $t_{r}$ is the total height of the bearing. The elastomeric bearings have a maximum 
shear strain capacity of $200 \%$ (400 mm) [12] and when exceeded, they will rupture with their stiffness reducing to zero.

The shear keys are modelled using multilinear springs with a tri-linear backbone curve as suggested by Silva et al. [15]. Two shear key strengths are investigated in this study. The sacrificial shear keys are assigned with an ultimate shear capacity of $2 \mathrm{MN}$, whereas the rigid shear keys are assigned with an ultimate shear capacity of $10 \mathrm{MN}$ (75\% of abutment pile lateral strength as required by Caltrans [9]).

The pile cap foundation is modelled using shell elements whereas the piles are modelled using frame elements as presented in Fig. 3(a). The piles are fixed to the pile-cap for the bridge with the FB foundation, whereas a non-linear gap element is used between the pile head and pile-cap to model the rocking interface. The gap element is assigned with compressive stiffness equal to the stiffness of the pile with an opening of zero. Pile group effects were not considered since the spacing between piles were greater than $3 \times \mathrm{D}$ (pile diameter $\mathrm{D}=1.2 \mathrm{~m}$ at the piers and $\mathrm{D}=0.8 \mathrm{~m}$ at abutments).

The surrounding soil is modelled using various soil spring properties to capture the soilstructure interaction effects during the seismic loading. The lateral stiffness of the clay was modelled using plastic springs with a P-y force displacement backbone curve as suggested by Welch and Reese [16]. The P-y soil springs are only activated during compression as they are modelled on either side of the pile to capture the separation between the pile and clay during earthquake loading. Furthermore, the skin friction of the pile is modelled using plastic springs with a T-z force displacement backbone curve as suggested by the API [17]. Both P-y and T-z uncoupled springs are assigned separately to the pile at $1 \mathrm{~m}$ intervals along its depth. Additionally, the pile-toe resistance is modelled using a linear spring with compressive stiffness equal to the stiffness of the Class A rock. All soil springs provide hysteretic damping using a kinematic hysteresis model.

\section{SITE CHARACTERISTIC AND SEISMIC HAZARD}

The bridges investigated in this study are hypothetically located at a high seismic region of Europe. Therefore, the following earthquakes were selected for this study: 1995 Kobe, 1994 Northridge, 1999 Chi-Chi, and 1976 Friuli. The properties of the ground motion records are displayed in Table 1. The bridges are founded on a $12 \mathrm{~m}$ deep layer of clay with properties consistent with Class D type soil underlined by Class A rock [12]. The European seismic hazard map was used to determine the PGA for the maximum considered earthquake of $2 \%$ probability of exceedance in 50 years $(\mathrm{PGA}=0.6 \mathrm{~g}$ ). The earthquakes are then scaled to the Eurocode- 8 target response spectrum displayed in Fig. 4, for a damping ratio of 5\% between the periods of $\mathrm{T}=0.05 \mathrm{~s}$ and $3 \mathrm{~s}$. Moreover, non-linear time history analyses were used to simulate the earthquake loadings. Rayleigh's mass and proportional stiffness damping was used with a 5\% damping ratio for the first three fundamental periods of the bridges [18], [19].

Table 1: Details of the selected ground motion records.

\begin{tabular}{ccccccc}
\hline No. & Earthquake & Year & Station & $\mathrm{M}^{* a}$ & $\mathrm{R}_{\text {rup. }}(\mathrm{km})$ & PGA $(\mathrm{g})$ \\
\hline 1 & Kobe & 1995 & Takatori & 6.9 & 1.47 & 0.618 \\
\hline 2 & Northridge & 1994 & $\begin{array}{c}\text { LA - Sepulveda } \\
\text { VA Hospital }\end{array}$ & 6.69 & 8.44 & 0.753 \\
\hline 3 & Chi-Chi & 1999 & CHY080 & 7.62 & 2.69 & 0.809 \\
\hline 4 & Friuli & 1976 & Tolmezzo & 6.5 & 15.82 & 0.35713 \\
\hline
\end{tabular}

Note: $\mathrm{M}^{*}$ a represents moment magnitude and $\mathrm{R}_{\text {rup. }}$ represents closest distance to fault rupture. 


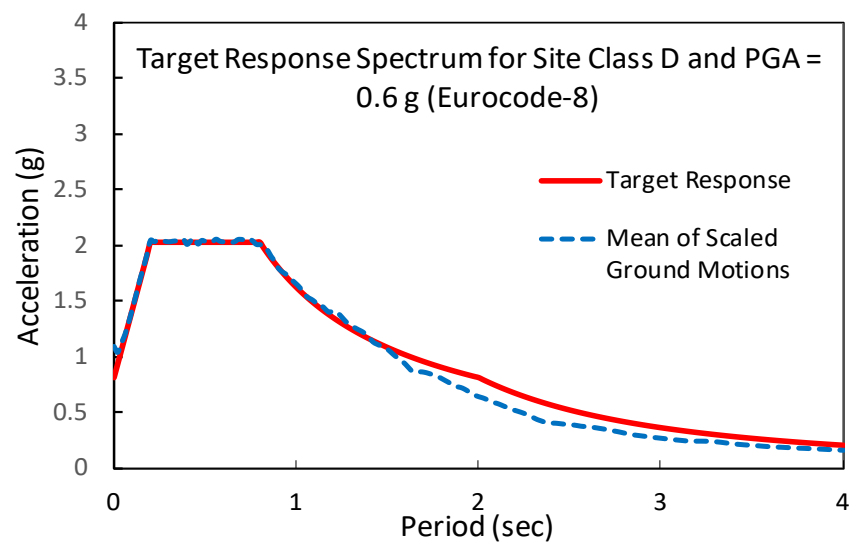

Figure 4: Response spectrum of Eurocode- 8 design spectra and the original ground motions.

\section{RESULTS AND DISCUSSION}

\subsection{Modal analysis}

A modal analysis was conducted for the bridges using Ritz vectors with a mass participation ratio of $98 \%$. The fundamental periods of all the bridges in the transverse direction were computed and presented in Table 2.

Table 2: The fundamental periods of the bridges.

\begin{tabular}{lccc}
\hline & $\begin{array}{c}\text { Period 1 } \\
\text { (Transverse-piers } \\
\text { in phase) }\end{array}$ & $\begin{array}{c}\text { Period 2 } \\
\text { (Rotation } \\
\text { about pier 2) }\end{array}$ & $\begin{array}{c}\text { Period 3 } \\
\text { (Transverse-piers } \\
\text { out of phase) }\end{array}$ \\
\hline RP-rigid & 1.82 & 0.625 & 0.31 \\
\hline RP-sacrificial & 2.21 & 1.23 & 0.52 \\
\hline FB-rigid & 0.413 & 0.34 & 0.24 \\
\hline FB-sacrificial & 1.06 & 1.02 & 0.413 \\
\hline
\end{tabular}

As can be seen from Table 2, the predominant period for all the bridges is the in-phase transverse displacement of the deck and piers, followed by horizontal rotation of the deck about Pier 2, and then the out of phase transverse displacement of the deck and piers. It is evident that the RP-sacrificial bridge has the largest natural period, followed by the RP-rigid, FB-sacrificial, and FB-rigid bridge. The RP bridges have a larger period when compared to the FB bridges due to the reduced lateral stiffness in the foundation and pier. Furthermore, the rigid shear keys reduce the natural period of the bridges as they provide much greater stiffness to the transverse translation of the deck when compared to the sacrificial shear key. This is because the rigid shear keys utilise the bending stiffness of the deck when resisting transverse loads. When referring to Fig. 4, It is evident that an increase in the natural period of the structure leads to a reduction of the inertial actions on the bridge. However, a larger structural period will result in larger displacements of the structure which can cause other failures in the bridge. 


\subsection{Non-linear time history results}

Non-linear time history analyses were conducted using four earthquake excitations scaled to the appropriate seismic hazard. The earthquake excitations are applied to the transverse direction of the bridges and their dynamic response is reported in Table 3.

\subsection{Pier bending moments}

Table 3 and Fig. 5 report the maximum experienced bending moment at the piers under the applied earthquake loadings. Due to the configuration of the bridge, the seismic response of only Pier 2 (refer to Fig. 1) is reported as it was determined to be the most critical pier. When referring to Fig. 5 and Table 3, it is evident that the RP bridges experienced much lower bending moments when compared to the FB bridges for all the earthquakes. This is because the RP bridges have a larger natural period and attract much smaller inertial forces as can be seen from Table 2 and Fig. 4. In contrast, the piers in the FB bridges experienced bending moments that exceeded their ultimate bending capacity $\left(\mathrm{M}_{\mathrm{ult}}=120 \mathrm{MN} . \mathrm{m}\right)$. Additionally, the results from the assigned flexural plastic hinges confirmed that the piers belonging to the FB bridge collapsed. This is because the structure's smaller period attracts larger inertial forces as can be seen from the target response spectra in Fig. 4.

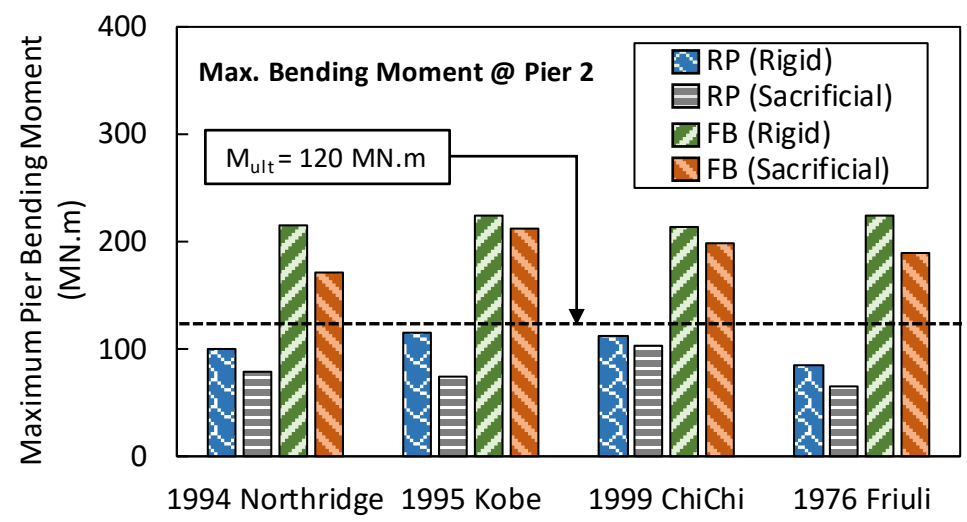

Figure 5: Maximum bending moment experienced at the piers under all earthquakes.

It is evident from Table 3 and Fig. 5 that the design of the shear keys affected the maximum bending moment experienced by the piers. The bridges with rigid shear keys at the abutments significantly increased the bending moment experienced by the pier for both the FB and RP bridges. The increased stiffness that the rigid shear keys provides for the transverse response of the bridges leads to a reduction in the structures natural period. Again, when referring to Fig. 4, a reduction in the natural period of the structure leads to an increase in the seismic response of the structure. Additionally, the increase in pier bending moment for both the RP and FB foundations occurring from Rigid shear keys were approximately equal for both bridges. The use of sacrificial shear keys to limit the forces at the abutment also reduces the inertial actions at the piers due to the prolonged period of the bridge. 


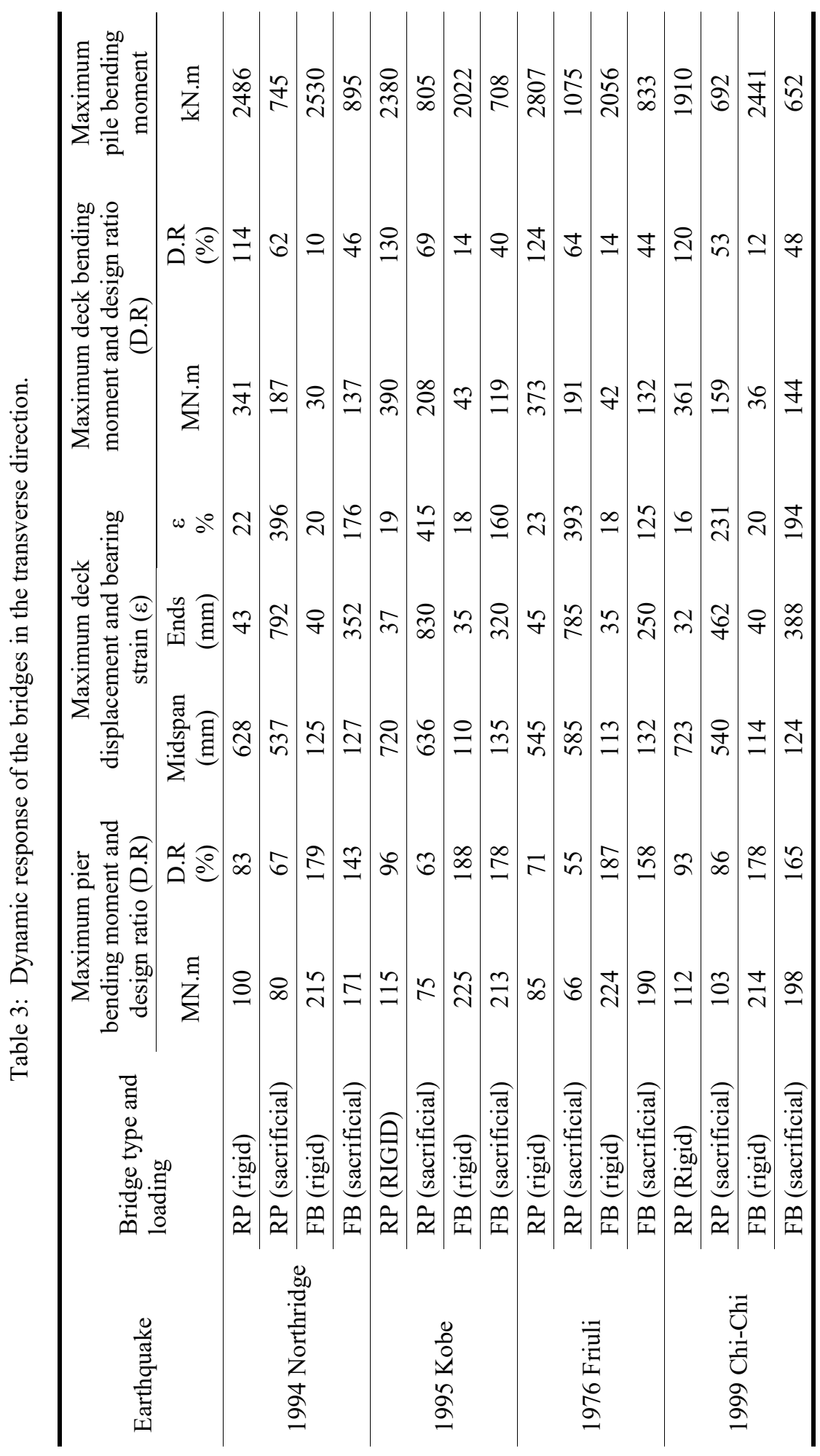




\subsection{Deck displacements and bending moments}

Table 3 and Fig. 6 report the maximum deck displacements experienced by all the bridges. It is evident that the bridges with the RP foundations experienced significantly larger deck displacements when compared to the bridges with the FB foundations. Additionally, Table 3 and Fig. 7 report the maximum bending moments experienced by the deck. It is evident that the maximum bending moments are not only affected by the type of foundation but also the shear key design.
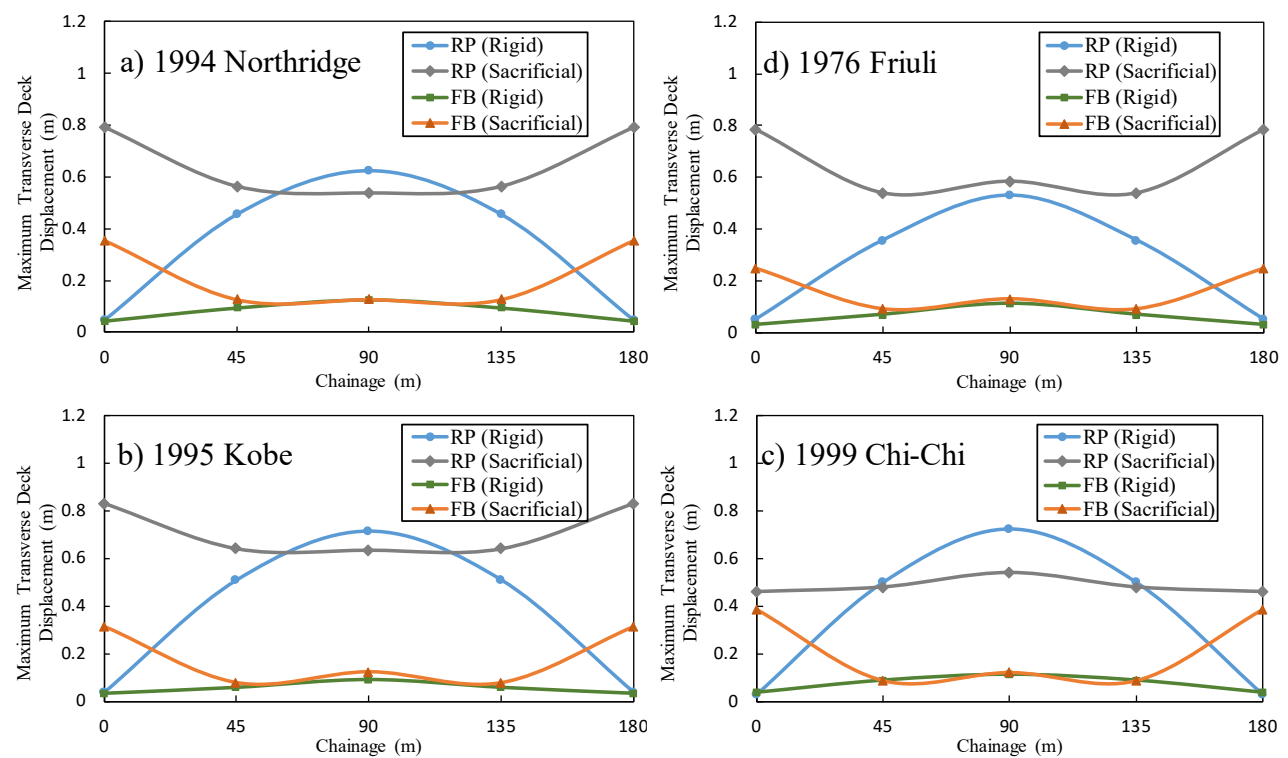

Figure 6: Maximum deck displacements along the chainage of the bridge. (a) 1994 Northridge; (b) 1995 Kobe; (c) 1999 Chi-Chi; and (d) 1976 Friuli.

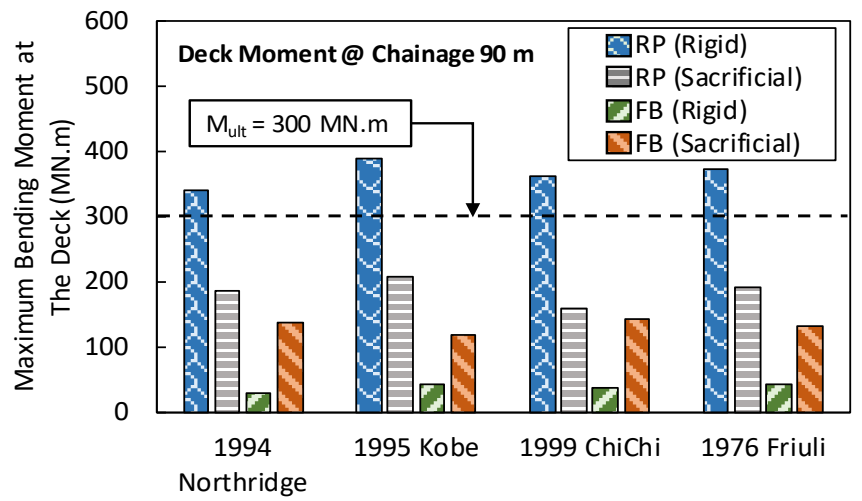

Figure 7: Maximum experienced bending moment experienced at the deck section at chainage $90 \mathrm{~m}$. 


\subsubsection{Comparison of the RP-rigid and FB-rigid bridges}

As observed in Table 3 for all the earthquake excitations, the RP-rigid bridge experienced a maximum deck displacement of $723 \mathrm{~mm}$ at the midspan of the bridge for the 1999 Chi-Chi earthquake. In contrast, the FB-rigid bridge experienced a maximum deck displacement of only $125 \mathrm{~mm}$ at the midspan of the bridge for the 1994 Northridge Earthquake. Both bridges experienced negligible deck displacements at the abutment due to the transverse restraint of the rigid shear keys which performed elastically throughout the duration of the earthquakes. The RP-rigid bridge experienced larger seismic displacements due to its larger natural period as it is more responsive to the low frequency signals of the earthquakes. Furthermore, the lateral stiffness in the bridge piers of the RP-rigid bridge provide significantly less transverse restraint to the deck due to foundation uplift. On the other hand, the FB-rigid bridge piers provide much greater restraint to the deck, preventing large displacements from occurring. The decrease in the lateral stiffness in the piers of the RP-rigid bridge makes the bridge deck behave similarly to a long span bridge, spanning from both abutments rather than spanning from abutments to piers or pier to pier.

Table 3 and Fig. 7 display the maximum bending moments experienced by the bridge decks. When comparing bending moments in Fig. 7 with the deck displacements in Fig. 6, it becomes evident that the large deck displacements promote more bending in the deck and as a result, experience significantly larger bending moment. As observed in Fig. 7, the RP-rigid bridge experienced bending moments in the deck that exceeded its ultimate bending capacity $\left(\mathrm{M}_{\mathrm{ult}}=300 \mathrm{MN} . \mathrm{m}\right)$ for all the earthquakes, with a maximum bending moment of $390 \mathrm{MN} . \mathrm{m}$ for the 1995 Kobe earthquake. The results of the assigned flexural plastic hinges indicate that the deck section failed, and the subsequent collapse of the span was experienced due to its inability to carry vertical dead loads. Again, the increased period of this bridge as well as the decreased lateral stiffness at the piers has led to the deck experiencing large displacements. The deck displacements are resisted by the bending action of the deck, with its bending shape presented in Fig. 6. On the other hand, the FB-rigid bridge experienced significantly smaller deck moments with a maximum deck bending moment of 43 MN.m for the 1995 Kobe earthquake. The deck bending moments are significantly smaller because the deck displacements are resisted by the fixed base foundation and piers. This is evident from Fig. 6 as the global displacement of the RP-rigid bridge is significantly larger than the bending of the FB-rigid bridge. The RP-rigid bridge not only experienced significant deck displacements but also significant bending actions which resulted in the flexural plastic hinging of the deck and collapse of the bridge. Bridges with this configuration require design provisions to account for these actions.

\subsubsection{Comparison of the RP-sacrificial and FB-sacrificial bridges}

As observed in Table 3 and Fig. 6, the RP-sacrificial bridge experienced a maximum deck displacement of $830 \mathrm{~mm}$ and $636 \mathrm{~mm}$ at the abutments and midspan of the bridge, respectively, under the 1995 Kobe Earthquake. Conversely, the FB-sacrificial bridge experienced a maximum deck displacement of $388 \mathrm{~mm}$ and $124 \mathrm{~mm}$ at the abutments and midspan of the bridge, respectively, for the 1999 Chi-Chi earthquake. Despite the RPsacrificial bridge experiencing considerably larger deck displacements, it is evident from Fig. 6 that both bridges have very similar deck deformation shapes and curvature as a result of using sacrificial shear keys. This is further confirmed in Fig. 7 as the maximum bending moments experienced by both bridge decks are very similar due to similar bending actions. The RP-sacrificial bridge experienced slightly larger deck bending moments due to the large displacement of the intermediate piers. Nevertheless, despite the type of bridge foundations, the observed bridge deck bending behaviour was similar due to the use of sacrificial shear 
keys. As a result of the large deck displacements experienced at the abutments, the elastomeric bearings experienced significant bearing strains. Maximum elastomeric bearing strains of $194 \%$ and $415 \%$ were experienced for the FB-sacrificial bridge and RP-rigid bridge, respectively. Despite experiencing similar bending behaviour of the deck, the magnitude of the displacements was very different. Significant bearing damage was experienced in the RP-sacrificial bridge as the maximum bearing strain of $200 \%$ was exceeded, resulting in rupture of all the bearings and permanent displacement of the deck. This is not only expensive to repair, but such failure can place the deck at risk of transverse unseating or span failure of certain types of bridge decks.

\subsubsection{Comparison of the sacrificial and rigid shear keys for each bridge type}

The RP-sacrificial bridge experienced significantly smaller deck bending moments when compared to the RP-rigid bridge as seen in Fig. 7. This is because the deck is not restrained at the abutment and therefore does not utilise its bending strength for recentring but rather relies on the foundations rocking ability. However, when referring to Fig. 8 for the displacement time history for the deck and abutment, it can be seen that due to the difference in stiffnesses at the abutment and piers, the deck experiences out of phase displacements which could increase bending of the deck. Given this bridge has a regular configuration, the out of phase bending is insignificant when compared to a bridge with an irregular configuration. Such a bridge could experience large deck bending and can experience flexural hinging damage of the superstructure as observed in the RP-rigid bridge. Similarly, the FB bridges experienced significantly larger bending moments at the deck after the shear keys fractured, hence, sacrificial shear keys are required to be carefully considered to avoid superstructure failure of the bridge.
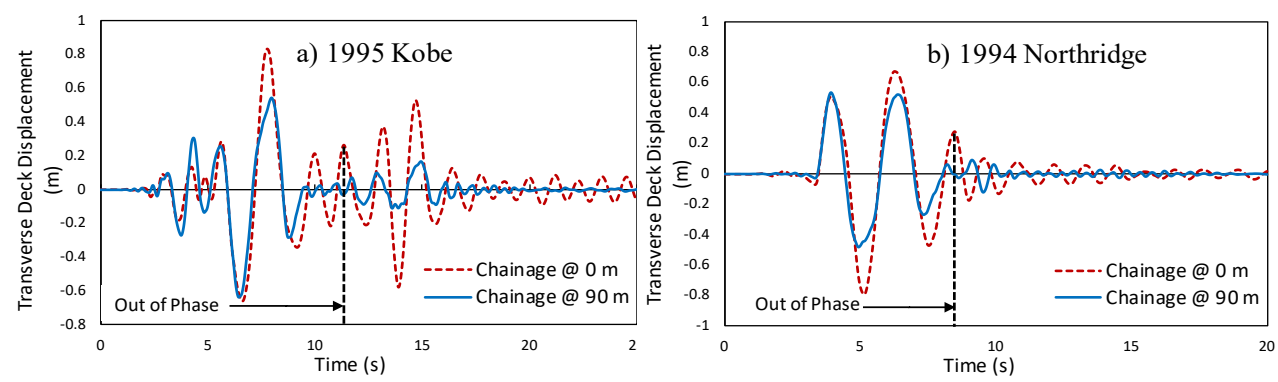

Figure 8: Displacement time history for the RP-sacrifice deck at midspan and at the abutment. (a) 1994 Northridge; and (b) 1995 Kobe.

\subsection{Pile bending moments}

Fig. 9 displays the maximum bending moments experienced by the abutment piles. It is evident that the RP-rigid bridge and FB-rigid bridge experience similar pile bending moments. Moreover, the RP-sacrificial bridge and FB-sacrificial bridge also experience similar pile bending moments. The type of bridge foundation has little effect on the abutment pile actions because the abutments are isolated from the deck by elastomeric bearings. The main forces generated by the superstructure are transferred to the abutment through the bearings and shear keys. Thus, the bridges with different foundation systems but identical shear key experienced similar actions to their piles. When comparing the FB bridge with the 
RP bridge with same shear key design, the FB bridge experiences slightly smaller or larger bending actions at the piles. This is because the FB bridge has a smaller natural period and attracts larger inertial actions to the structure, but the large deck displacements from the RP bridge also transfer shear forces through the bearings and shear keys. Both types of seismic actions were similar and varied based on the type of earthquake loading which resulted in piles to having either smaller or larger bending actions. Moreover, when comparing the rigid shear keys with sacrificial shear keys, it was evident that the bending actions were increased by more than double when the rigid shear keys are used. Therefore, a bridge with rigid shear keys would require significantly more piles than a bridge with sacrificial shear keys.

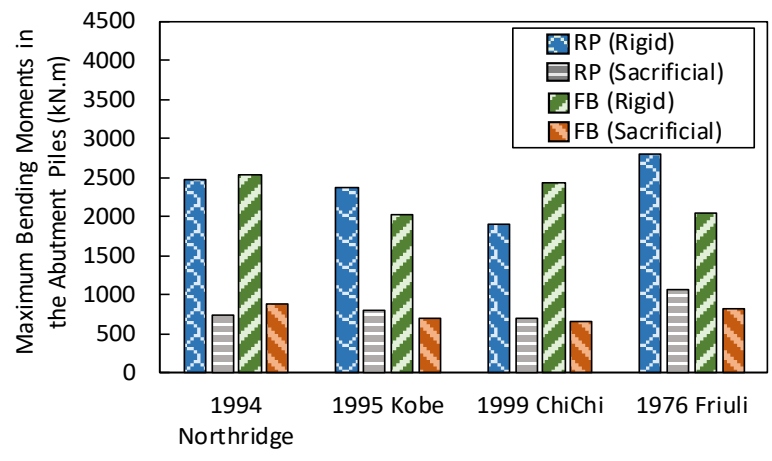

Figure 9: Maximum pile bending moments.

\section{CONCLUSIONS}

This paper investigated the effect of transverse earthquake excitations on the seismic response of rocking bridges with two different shear keys including: (1) sacrificial shear keys; and (2) rigid shear keys. The results showed that the rocking pile bridges experienced smaller inertial actions to their piers whereas the conventional based bridges experienced significant plastic hinging at their piers resulting in the global collapse of the bridge. Nevertheless, the rocking pile bridges experienced significant deck displacements and, hence, severe damages at the superstructure. When the rigid shear keys were implemented, the deck experienced severe flexural plastic hinging resulting in the collapse of the span. This bridge also experienced significantly larger bending moments in its abutment piles. On the other hand, when sacrificial shear keys were adopted, the bridge experienced less bending to the deck, but significant displacements at the abutment which ruptured the elastomeric bearings. It is concluded that bridges with rocking pile foundations can experience significant deck displacements when subjected to transverse earthquakes, and design provisions are necessary to account for the additional forces experienced to the superstructure and abutment.

\section{REFERENCES}

[1] Mehrsoroush, A. \& Saiidi, M.S., Cyclic response of precast bridge piers with novel column-base pipe pins and pocket cap beam connections. Journal of Bridge Engineering, 21(4), 04015080, 2016.

[2] Antonellis, G. \& Panagiotou., M., Seismic response of bridges with rocking foundations compared to fixed-base bridges at a near-fault site. Journal of Bridge Engineering, 19(5), 04014007, 2013. 
[3] Xu, R. \& Fatahi, B., Geosynthetic-reinforced cushioned piles with controlled rocking for seismic safeguarding. Geosynthetics International, 25(6), pp. 561-581, 2018.

[4] Anastasopoulos, I. et al., Soil failure can be used for seismic protection of structures. Bulletin of Earthquake Engineering, 8(2), pp. 309-326, 2010.

[5] Antonellis, G. et al., Shake table test of large-scale bridge columns supported on rocking shallow foundations. Journal of Geotechnical and Geoenvironmental Engineering, 141(5), 04015009, 2015.

[6] Eatherton, M.R. et al., Design concepts for controlled rocking of self-centering steelbraced frames. Journal of Structural Engineering, 140(11), 04014082, 2014.

[7] Chadwell, C.B., Fenves, G.L. \& Mahin, S.A., Near source earthquake effects on the ji lu cable-stayed bridge in the 21 September 1999 Chi-Chi Taiwan earthquake. National Science Foundation, 2003.

[8] Shen, X. et al., Seismic performance of transverse steel damper seismic system for long span bridges. Engineering Structures, 141, pp. 14-28, 2017.

[9] Caltrans, Caltrans Seismic Design Criteria Version 1.6, California Department of Transportation, 2010.

[10] Goel, R.K. \& Chopra, A.K., Role of shear keys in seismic behavior of bridges crossing fault-rupture zones. Journal of Bridge Engineering, 13(4), pp. 398-408, 2008.

[11] Xiang, N. \& Li, J., Seismic performance of highway bridges with different transverse unseating-prevention devices. Journal of Bridge Engineering, 21(9), 04016045, 2016.

[12] European Committee for Standardization, Eurocode 8: Design of Structures for Earthquake Resistance - Part 2: Bridges, 2005.

[13] Hassoun, M. \& Fatahi, B., Novel integrated ground anchor technology for the seismic protection of isolated segmented cantilever bridges. Soil Dynamics and Earthquake Engineering, 125, 105709, 2019.

[14] Fatahi, B. et al., Three-dimensional response of neighboring buildings sitting on pile foundations to seismic pounding. International Journal of Geomechanics, 18(4), $04018007,2018$.

[15] Silva, P.F., Megally, S. \& Seible, F., Seismic performance of sacrificial exterior shear keys in bridge abutments. Earthquake Spectra, 25(3), pp. 643-664, 2009.

[16] Welch, R.C. \& Reese, L.C., Lateral Load Behavior of Drilled Shafts, University of Texas at Austin, 1972.

[17] API, Recommended practice for planning, designing and constructing fixed offshore platforms: Working stress design, 2000.

[18] Xu, R. \& Fatahi, B., Novel application of geosynthetics to reduce residual drifts of mid-rise buildings after earthquakes. Soil Dynamics and Earthquake Engineering, 116, pp. 331-344, 2019.

[19] Fatahi, B. et al., Three-dimensional simulation of seismic slope-foundation-structure interaction for buildings near shallow slopes. International Journal of Geomechanics, 20(1), 04019140, 2020. 